\title{
Partnerships in health research: Experiences from a developing country
}

\section{Banjara MR}

Lecturer of Microbiology, Central Department of Microbiology, Kirtipur, Kathmandu, Nepal

$P^{1}$ artnerships research is the collaboration between the scientists and technologists of the developed countries (North) and poorer countries (South). Until now, the southern partner has been viewed as the receiver and the northern partner as the giver. Oldham (2005) pointed out the advantages of international collaborative research works with some disadvantages such as leadership of northern partner and acting as assistant by southern partner due to unequal research capacity, pressure of northern partner in selecting research agenda, and increasing brain drain from the south.

The Netherlands Development Assistance Research Council (RAWOO), The Swiss Commission for Research Partnership with Developing Countries developed the principles of partnership in research. The guideline developed for Good Clinical Practice (GCP) mentions ethical standards for designing, conducting, recording and reporting trials that involve human subjects to assure the rights, safety and well-being of the research participants. Besides, World Health Organization/Southeast Asia Regional Office also discussed and developed the guideline for partnerships research in the region in 1999. In Nepal, Nepal Health Research Council (NHRC) has developed the National Health Research Policy, Health System Research in Nepal and Ethical Guidelines to address research ethics and priorities of research. Despite these efforts; however, these are not being followed for research in many of the developing countries such as Nepal.

Lack of good networking between the partners, clear division of the roles and responsibilities, equitable, respectful and sustainable partnership are the current limitations to be successful partnership. Past research collaborations have bitter experience for the developing countries since most of the researches were controlled by the scientists of the developed countries. In many instances, the scientists of the developed countries have published papers, reports of the data of the developing countries without acknowledging them. Till now, proposals are developed highlighting the poverty and disease burden in the developing countries and papers are published with each title mentioning poor country or poor people or developing country. The people who provide data and the local advisors who help in conducting research usually get nothing. Several papers utilizing the data from Nepal have been published without the names of Nepali researchers. Some papers are published with information over estimating than the real. Many researches are conducted violating the ethical principles. The paper published by Gaillard (1994), considered by many to be a charter of north south partnerships for true partnership, is still not being followed. Besides, research partnerships have donor driven priorities and systems, difficulties with donor procedures and co-ordination, and delays in disbursements. NHRC is the national organization to provide national ethical approval and supervise the researches that are done in Nepal. However, if we look for several publications, ethical approval has not been taken from NHRC though it has been taken from institution of the developed countries.

As mentioned by Weatherall et al. (2005), to generate better information of the disease and for the improvement of its management globally, there is a need for developing sustainable research partnerships between rich and poor countries. International and bilateral agencies funding research in developing countries should involve a research capacity strengthening (RCS) in their projects to ensure the sustainability of these. The training of the young researchers should be promoted in the national institutional framework where the research will be conducted.

For better collaboration between developed countries and developing countries, much more investment is needed for an innovative approach to research on health systems; health research must be managed more effectively to strengthen health systems and research capacity e.g. in molecular research, well designed experimental and epidemiological research; and ethical principles and principles of partnerships research should be strictly followed. The emphasis should be placed on translating knowledge into action to improve public health of the developing countries. Before disseminating research findings through publications, these should be shared with policy makers of the country so that these can be implemented into action for the benefit of the people. 


\section{References}

1. Gaillard JF. North-south research partnership: is collaboration possible between unequal partners? Knowledge and Policy 1994; 7: 2.

2. Oldham G. International scientific collaboration: a quick guide. Policy Brief, SciDevNet, 2005.
3. Weatherall D, Hofman K, Rodgers G, Ruffin J, and Hrynkow S. A case for developing NorthSouth partnerships for research in sickle cell disease. Blood 2005; 105: 921-923. 